\title{
Dialogue 2: Implications, challenges and opportunities of ODA graduation for countries in transition
}

According to current DAC rules, countries graduate from being eligible to receive ODA when they have been classified as high-income countries for three consecutive years by the World Bank. However, the group of countries projected to reach this stage by 2030 is highly diverse: it includes countries with small populations but stable economic conditions, like Botswana, Gabon or Costa Rica, medium-sized growing economies like Colombia and Malaysia, regional powers and G20 members such as Brazil and Turkey, and also the global superpower China. Therefore, the implications of ODA graduation for these countries differ widely, depending on the country's size and economic strength, its internal challenges and geopolitical importance.

Contrasting the perceptions of Uruguay, which graduated from ODA in 2018, Mexico and China, both of which have been projected to graduate by $2030^{45}$, we explore particular views on the topic. How have these countries experienced the process of graduation or how are they preparing for it? What are their needs and expectations, in the process as such and towards international partners? What are the challenges and opportunities surrounding ODA graduation? Highlighting each country's individual perspective, we want to discuss the transition towards becoming a provider, a potential shift in their identities and positioning in the system of international development cooperation, and their vision for a post-ODA world.

The discussion was held between Noel González Segura, Deputy Head of the Mission of Mexico to the European Union, Belgium and Luxembourg, Xiaojing Mao, Senior Research Fellow at the Chinese Academy of International Trade and Economic Cooperation, and Karen van Rompaey, Knowledge Manager at the Uruguayan Agency for International Cooperation. It was facilitated by Carolina de la Lastra, a Chile-based development consultant, and Juliane Kolsdorf, editor of this publication. ${ }^{46}$

Let us begin by talking about how you would interpret the graduation process from the different perspectives of your countries. We all know the technical explanation of the OECD and the per-capita-income criterion. Karen, as a

46 For better distinction from the discussants, the inputs and questions by the facilitators are displayed in italic without naming the respective person. 
pioneer in graduation, how was the process? How were you prepared and what consequences have you experienced since graduation?

Karen van Rompaey: I consider that the process of "graduation" lacked clarity and formality. We learned that Uruguay was in the process of being graduated from ODA through our regional partner Chile ${ }^{47}$, because Chile is a full member of the OECD and they had been filled in with this information. The process at this stage was that every time the Development Assistant Committee revised the list of countries eligible for ODA, they would put an asterisk in the list, and, in very small print, they would put the names of the countries that were in the process of graduation. This was a rule that we were not aware of. So, if we had not had our close relations with Chile, we would not even have been properly informed until who knows when. Of course, as Uruguay had been classified as a high-income country by the World Bank, we were aware that this would entail some changes, but we did not know how fast these changes were going to happen and we were not aware of the rules of the DAC since they are a closed group. And it was not only the Uruguayan government that was not aware of that rule, but also our cooperation partners on the ground. It was something they were maybe predicting for the future, but the future was coming faster than we all thought. So, early in 2016 there was no explicit exit from ODA strategy on the part of the government, but there was also no strategy from the DAC donors to support Uruguay during the graduation process.

When we realised that we were going to be graduated from ODA, we started to ask ourselves: What does this imply? What are the consequences of being graduated from ODA? What are the wider implications? Are we going to be perceived as a 'developed' country now? Are we going to have to give 0.7 per cent of our GDP to others? We started to seek documents or studies, but there were none. In consequence, we thought this was something that really needed to be studied further. Some people researching at universities were starting to look into this matter and we formed alliances with them so that they could provide us with thoughts and information on the wider consequences of being graduated as a basis for informing our policymakers. Was it good news? Was it bad news? What was behind the title of being 'graduated from ODA'? From that moment on, we defined a two-fold strategy: advocacy at the international level and a white paper ("Política de Cooperación Internacional de Uruguay para el Desarrollo Sostenible al 2030") together with our national stakeholders and in dialogue with those DAC donors on the ground who acknowledged that Uruguay still needed to strengthen capacities to transition towards sustainable development. 
From my perspective, the process was somewhat frustrating because it was automatised and unilateral. We wanted to have a conversation with the donors' community on this. And we thought that by sending a letter, a formal note to the president of the DAC, we were going to have an opportunity to explain our concerns and discuss this matter. It was going to be the first graduation of countries since the 2030 Agenda on Sustainable Development had been adopted. And that Agenda also changed the way the international community perceives development. There is a consensus now that sustainable development is not about economic growth, but that the perspective needed to be widened and that sustainable development is multidimensional and global in nature. The momentum was ideal to have that conversation, but we were not able to have this conversation. Chile was allowed to participate in the DAC meetings, and they were able to make the case, but there was no room for a real conversation and the process was fast; we were graduated the following year. Antigua and Barbuda, which were also on the asterisk list with us, did not graduate because of the hurricane which devastated the islands, showing us that some countries are, despite their per capita income, very fragile and vulnerable to these external shocks and that GDP per capita is not a good indicator of the development level of a country.

In my view, graduation has been rather untimely. It is true that Uruguay had been growing steadily for the previous ten years but at the time we were graduated, the country had started to slow down its economic growth in 2017 and to stagnate. In a sense, we were cut off from ODA when we started needing it again. Of course, Uruguay has never been dependent on aid. Aid was never about how much money donors gave to the country. Aid for us has always had a strategic value that is beyond its economic worth. It is about agenda setting; it is about putting all the people/stakeholders together that can design the best policy to solve a problem. It is about providing for public goods overall and strengthening capacities for sustainable development; it is not about the money that it brings in, but the knowledge and the facilitation role that comes with it. If that is taken away, important topics like, for instance, the environment and human rights, are most probably going to be neglected in the overall budgetary struggle, and the most vulnerable groups of the population are going to be left behind. With the support of international cooperation, we had made sure that these topics were talked about, capacities were strengthened and some of the most pressing issues were addressed with the facilitation of international aid.

In addition, the decision to graduate Uruguay and Chile was also decontextualised because it was not the same as when Eastern European countries graduated from ODA. They received structural funds from the EU afterwards or they even had transition funds for a few years too. We graduated in a region where we do not have alternative support mechanisms. We had MERCOSUR, 
which has a structural fund, but MERCOSUR's structural fund is now in difficult circumstances. The context of a country has to be taken into account and, in our case, it was not.

Finally, graduation seems incoherent and unfit for purpose if you look at the bigger picture. We have agreed, all of us, to achieve 17 global sustainable development goals by 2030, and no one can be left behind in the process. Of course, the ones that have the lesser capacities and greater needs, need to have the most support, but that does not mean that others should have the strategic support they were given taken away. In my view, this does not correspond to the purpose we all agreed on, that is, to make a transition towards global sustainable development, which is a really urgent matter.

Noel, how is the process now going in Mexico? Do you already feel a withdrawal effect? How are you managing this process? And have you been able to learn from what happened to Uruguay?

Noel González: Indeed, I think that we have learned. We have been having this discussion for a while now; the first debate that I can recall on this issue started in 2007/2008 in some ministerial meetings on the issue of middle-income countries that took place in both San Salvador and Madrid. The idea of transition comes from this graduation from low-income to middle-income and then from middle-income to high-income status. I can understand the discussion, even from an ethical perspective, because I think that in many donor countries, within these countries in their constituencies, they request that they concentrate on those countries that are most in need of international support.

However, I think that the discussion is being misunderstood from this perspective. Some of the ideas and experiences that Karen just shared were very telling. There is not a very clear road map for graduation. We do not really know how to cope with that. Mexico will, in fact, 'graduate' even without reaching the income level status that is required for graduation because we have already been told that our bilateral programmes are ending. But we have not become a high-income country yet. So, why should we have to receive fewer resources if we have not actually changed our development status? Even our income status is the same as it was before; it has not evolved in any significant manner. There are a lot of contradictions in this concept of graduation, which we think is more related to a political concern than to a real technical concern. I personally do not think it is based on facts; I think it is based on a misunderstanding of development on the part of some countries. There are countries that are more 'purist' in the sense that they would like to concentrate 100 per cent of their development cooperation on low-income countries or least developed countries. But the discussion is very easy to understand when you put it next to some of the discussions that you have within the countries which are providers of development cooperation. For instance, if you have that discussion in the UK 
or in the US and you give so many million dollars or pounds to a country abroad, why do you not give them to those in need within your own country? And then, the answer is very simple: If we spread the resources that we give to other countries, the benefits to our national population will be marginal. Basically, it would be, let us say, an increase of one dollar per student or one dollar per person, which is not bad if these people are in need of help; it is one dollar more but then, if you see it as development impact across the world, it is basically not significant. So, this idea comes from a difficult misunderstanding of the technicalities of development cooperation.

But we have been having these discussions for a few years due to, again, mostly political misperceptions; we are moving in the direction of graduation and we are preparing for that. And basically, we are trying to see how we can shift from, for instance, bilateral to bi-regional development cooperation programmes. We are moving towards different mechanisms of cooperating with donor countries. For instance, we are looking at co-financing certain programmes; we are looking at triangular cooperation; we are looking at horizontal programmes. We are also looking at regionalising within Mexico itself, taking a look at regional, sub-regional or subnational programmes, trying to focus on those regions which are most in need within our own country, like the states in the south-west of Mexico, Oaxaca or Chiapas. We are also trying to work on the narrative of development cooperation; for instance, I am sure that you have heard about the effort Mexico is undertaking in Central America to address the issue of forced migration from Central America to Mexico and then on to the United States. We are trying to convince our international partners that we need to work together in a more structured manner in order to create better conditions for countries nationally before we have to deal with very delicate issues like forced migration that have political but also humanitarian implications, implications for all the administrations that are affected.

So basically, after this long answer, the short answer is: We know that it is coming. We think that this is happening for the wrong reasons. We feel a certain frustration because we have not been able to communicate or our partners have not been open to having this discussion, notwithstanding the efforts that we have been undertaking. And we are adjusting our strategies to make the most out of the situation that we know will come.

Xiaojing, China has also been changing a lot. How has China been experiencing the process of moving towards graduation? Have some of the forms of cooperation changed in this context?

Xiaojing Mao: China, as an upper-middle-income country, is still on the DAC list of countries eligible for ODA. Several years ago, especially after China had hosted the Olympic Games in 2008, a lot of donors witnessed the development of China, so they began to stop providing new assistance to China. So, even 
though China has not yet graduated from the DAC recipient list, ODA to China has already been reduced. I think the net disbursement of ODA to China is already negative because most of ODA is provided in the form of concessional loans instead of grants. If I remember correctly, around 80-90 per cent of all the aid to China are loans, and China is already now repaying more loans than it is receiving aid from the international community.

That is the status quo of China in receiving aid. Many Chinese institutions which used to receive aid from the international world were also somewhat surprised when the donors suddenly stopped their aid to China. China used to receive quite a constant and comparatively large amount of ODA, which was channelled to these institutions. In my more recent interviews with them, they were a bit surprised about aid not coming in anymore, especially for those ministries working on specific sectors like agriculture, health or disaster preparedness. It was not a good situation for them without either financial support or technical support coming in.

When the traditional donors stopped their aid to China, they turned to seeking trilateral cooperation with China. The UK had some trilateral cooperation projects with China, but those funds cannot be used for China. They cooperate with Chinese institutions, but for the benefits of other developing countries. I participated in a mid-term review of UK trilateral cooperation projects with the Ministry of Civil Affairs of China and, to begin with, they did not understand the concept. They thought the money was intended for the Ministry of Civil Affairs, that it could be used in China. They only understood when the UK explained that this is not traditional aid anymore and that it must be used in third partner countries. It took some time for the Chinese institutions to understand that China had already been taken off the recipient lists of many donors.

As a researcher, and you also asked about the concept of graduation, I reflect on the purpose of graduation. Probably the DAC wants to encourage its members to focus more on low-income countries which they think may need aid more. But there have also always been debates in the international community about whether ODA should focus more on poor countries or poor people. According to the UN's criteria, China still has a large poor population, just like India, with the second largest population in the world. Many donors are phasing out their aid to India, but India still has a large poor population and is, in fact, a lower-middle-income country, just like some other emerging economies. So, when we are thinking of graduation from ODA and its main purpose, how should we address the poor populations in those graduating countries? You also mentioned small island countries, which remain very vulnerable to natural disasters, even if they graduate or reach a high-income status, and then they may relapse into an upper-middle-income country or even a middle-income country. How should their needs be addressed by the international community? 
From my point of view, the topic of graduation needs more discussion, also for traditional donors. After they all phased out their aid to China, they engaged in trilateral cooperation with China as a donor, but I am not sure what kinds of cooperation other countries, like Uruguay or Botswana, can maintain in development areas. There are a lot of concerns in this respect.

Karen outlined that the problem in graduation for Uruguay is not the loss of financial resources, but losing access to policy dialogue, to knowledge exchange, etc. In the case of China, you mentioned the actual transition-regardless of its official graduation - since 2008. What were the factors that were missed by the Chinese when donors withdrew from the country? I can also imagine that - with China being China - there is great interest among former donors to come back and strengthen international cooperation ties in different ways. How is China going into these new forms of cooperation?

Xiaojing Mao: We are currently working on a research project on EU-China trilateral cooperation, where we conducted interviews with Chinese ministries and with the institutions in charge of international cooperation in their sectors. For those phased out of ODA, like Karen mentioned, aid not only meant financial support but much more. They valued the technical exchange, the sharing of experience, learning and management skills development, which came through the aid from traditional donors. Even in the 1990s, when China was the largest recipient country, ODA only accounted for a small proportion of China's either GDP or even total national budget. The value for the Chinese institutions was much more in the incoming knowledge and management skills.

In many Chinese ministries, there were also institutions established to manage the incoming aid. After all that had been phased out, they needed to find new tasks and many of these institutions are now active in applying for the implementation of China's own aid projects. This way, they hope to support other developing countries by using the knowledge they gained through the incoming aid. From my point of view, this is also an area where China can continue its collaboration with traditional donors, through trilateral or diversified kinds of cooperation. There is still a lot of potential in this.

We have heard about different forms of cooperation and institutional changes. What should international relationships and international cooperation systems look like in a post-ODA world? How do you see it? How should it be from the side of your countries and also from the traditional donors' side?

Noel González: The world is already moving in a direction where you have a more horizontal setting in international relations. In the past, we were living in a world where mostly those so-called 'liberal democracies' would set the pace, establish institutions and set the standards. But we are moving away from that world. By moving towards a more horizontal approach to development 
cooperation, we are moving towards a more horizontal world overall. I do not think that is particularly bad; on the contrary, we as developing countries have been requesting to play a more meaningful part in the setting of international rules and standards for a while. That is perhaps what we are moving towards, but I also hope that we move towards a world where, while being more horizontal, we continue to cooperate, continue to exchange and continue to find ways to support each other's development efforts. Technological exchanges, scientific exchanges, student exchanges and so forth are beneficial for everybody. We have many issues to tackle as humanity; for instance, climate change is clearly one concept that we need to work on together because otherwise, we will simply not be very effective. So, if we establish more protectionist rules or if we establish mechanisms in which we must each solve our problems alone, then that, in my view, is not conducive towards being better off as humanity overall. We still need to make significant steps towards achieving the SDGs in 2030, and that requires efforts in international development cooperation. So, from my point of view, we are moving towards a more multipolar, more horizontal world. My hope is that this will not entail fewer cooperative international arenas; on the contrary, I think that we need to work more on the basis of cooperation and exchanges to achieve our common goals.

Could you illustrate the institutional changes to us? You already mentioned the bilateral funds that you were establishing with other countries. What is changing in the institutional world in Mexico regarding ODA?

Noel González: Mexico is a country that has been working on international development cooperation for decades, our first institutional arrangements on technical cooperation go back to the seventies. We established the Mexican Agency for International Development Cooperation (AMEXCID) in 2011 and we have been working on the basis of the national law on international development cooperation, which gives a lot of strength and solidity to the work that we undertake. We have a certain autonomy in terms of budget. In my view, lately we have been moving away from being more of a coordinating actor in Mexico. We have been organising, for instance, the bilateral commissions that were responsible for establishing the bilateral development programmes with our partners, both developed and developing countries, in line with more traditional schemes of cooperation but also South-South cooperation towards other Latin American countries. We have been moving away from that role, without forsaking that role, towards more of an implementation role. By doing so, we are becoming more active on the ground. Notably, we have been working on the implementation of programmes in Central America. We have been planning for a year and are now starting the implementation of some programmes which are being directly implemented by AMEXCID on the ground. That means working with the local authorities in order to establish the goals, the rules of cooperation 
and then the implementation of the programmes. Normally, what you would do in the past would be to rely on an international organisation, for instance the United Nations or an NGO that would be our implementation partner, but now Mexico is undertaking this work as well.

We are becoming more of an implementation agency, but at the same time we are not losing grasp of political discussions - with the establishment of the bi-regional programmes, for instance with the European Union, establishing the way that we are going to cooperate, with Germany, with France, with Spain or with other main development partners, on the ground. We continue to work with them in order to establish priorities and bilateral development programmes. These programmes are going to change in nature and scope, as we were discussing before. Instead of having big umbrella programmes under which we would establish projects within Mexico, we will be working in a more specific and targeted manner, for instance, working on issues like sustainability or water management. We are going to have to work in a more coordinated manner with all actors, not only the federal administration in Mexico, but more with local authorities in order to achieve more specific goals.

In my view, those are the most notable changes that are going to be operationalised in the coming years: moving away from being a coordination agency towards becoming an implementation agency, and working in a more focused, more results-based way on the ground with, for instance, subnational authorities.

Karen, looking into post-ODA relationships, a more horizontal setting and a continuation of cooperation, what is your perspective? What has happened in the case of Uruguay, which is a small country and may experience a different situation than Mexico and China?

Karen van Rompaey: If you want to understand this post-ODA world, there are some conceptual issues around 'graduation' that need to be further addressed. The concept of 'graduation' is based on a misunderstanding of what the nature of development is. The DAC graduation is based on the idea that a country magically develops when it surpasses for three consecutive years an arbitrary threshold put forward by the World Bank in the eighties, through a methodology that has never been sufficiently explained, nor adequately updated. Martin Ravaillon, who used to be the World Bank's head of research, has been very critical of the bank's income classification because of its lack of clarity, rigor, and transparency. The World Bank sought to establish in the 1980s a country classification by "finding a stable relationship between a summary measure of well-being and economic variables and the annual availability of Bank's resources", as per stated by the Bank itself. However, there is no documentation on the World Bank's site about this "stable relationship" and how it has changed 
over time. According to Ravaillon ${ }^{48}$, it is also unclear what a "stable relationship" means and why the Bank's resources (in the 1980s) are relevant to defining whether a country is a LIC, MIC, or HIC, either in the 1980s or now. Moreover, he has criticized the bank's use of the outdated Atlas method instead of purchasing power parity exchange rates for currency conversion. Moreover, a research paper by Fantom and Serajuddin from the World Bank Group argued in 2016 that the World Bank's methodology for keeping the per capita thresholds 'fixed' in real terms does not fully reflect inflation experienced by low and middle income countries, resulting in thresholds that are too low and may have pushed countries into higher income groups prematurely. ${ }^{49}$ But unfortunately, this income classification of countries has been very influential for operational and analytical purposes and is the sole criterion that informs the process of ODA graduation.

In the case of Uruguay, the good news is that the country has been steadily growing with sound macroeconomic and social policies that improved the quality of life of many people in Uruguay. That is the good news. But, having graduated from ODA, and the knowledge and the facilitation role it brings with it, only because of our income level, is an extreme measure. We do not see ourselves as a graduated country; we identify ourselves as a country in transition towards sustainable development and we see ourselves as a country with a dual role in international cooperation. Uruguay has been strengthening its capacities and has started to play a more pro-active role in South-South cooperation and triangular cooperation, but even in South-South cooperation, Uruguay has a dual role. We also receive cooperation from other southern countries, even from other countries that could be considered to have a lower development level than Uruguay. But all countries learn lessons and make progress in different policy arenas and seek to solve common problems together. This is what we share through South-South cooperation, and this is the ethos that the 2030 Agenda requires.

Coming back to the post-ODA international relationship question, Uruguay is a small country, has high human development indicators and has been progressing in the closing of some of its most pressing structural gaps, but it also has great challenges ahead if we really want to transition towards a more sustainable model of development. Our economy is still heavily organised in terms of intensive exploitation of natural resources, which really needs to change. Sustainability needs to be embedded in the way we produce and consume, otherwise it is going to jeopardise not only Uruguay's development but also the achievement of sustainable development regionally and globally. For instance,

49 Fantom/Serajuddin 2016. 
most of our technical experts on the environment are still funded by international cooperation projects and through the Global Environmental Facility (GEF). In Uruguay, the state does not yet have this capacity itself. It is all provided by international cooperation, and this needs to go on for a few more years until we really find the ways to embed this within our own domestic resources. Gender violence, for instance, was declared a national emergency last year and we still do not have the adequate institutional capacity and resources to tackle this problem and make the necessary cultural shift to address this very big issue. And yet, we are no longer eligible for the UN Trust Fund to End Violence against Women (UN Women) because only ODA eligible countries can apply to this fund.

We lack both the connection to international knowledge and the access to financing, because for instance as far as the environment, climate change adaptation and mitigation, and natural resources management, conservation or restauration are concerned, we do not have the funds so far. The economy needs to grow to provide more resources, and the country also needs to become more conscious that these areas need to have a higher priority level in the budgetary struggle. We need funds for the environment and climate change, for global public goods in general. Still, technical cooperation is also needed, and in that respect funds and technical cooperation often come hand in hand. They are never purely funds and purely technical cooperation. They come entangled, in most cases.

What else do you think has changed, for instance in terms of communicating, of negotiating? Because Mexico is a regionally very strong country, China is a superpower and many countries are striving to have contact with China. What is the case for a small country like Uruguay? Do you think something has changed in your general relations in this post-ODA world?

Karen van Rompaey: Well, it has only been a year since we were graduated but, yes, we were going to be excluded from the regional cooperation of the European Union because the EU's international development instrument was linked to the ODA list of eligible countries. Our then President Vázquez wrote a letter to Jean-Claude Juncker, then President of the European Commission, saying that we did not want to be graduated from the regional cooperation of the European Union, because we did not want to be excluded from a set of strategic dialogues that the EU is promoting through regional cooperation, surrounding climate change and security - like for instance the COPOLAD programme, which is about fighting transnational organised crime -, migration and all the social cohesion topics that the EUROSOCIAL programme is addressing in the region.

There is something else, which is not directly related to ODA but has an indirect impact: Uruguay is no longer a middle-income country. Where does it 
stand in all the political negotiations in the UN, for instance? Where do we align ourselves? Are we a developing country? Are we a developed country? Are we part of the G77? Are we part of the group of middle-income countries? Our graduation from ODA has also led to us living slightly in limbo. So, we are also trying to make sense of these political implications of graduation from ODA, but it is a bit too soon to grasp all the effects of graduation.

After the graduation, we managed to negotiate with the European Union and we are back in regional cooperation; they have also maintained the funds for our civil society, and we are negotiating a bilateral co-fund to address Uruguay`s transition priorities and to keep the political dialogue vibrant. We have also managed to negotiate with Japan to keep the funds and cooperation schemes that they had with Uruguay, including triangular cooperation. Scholarships and scientific cooperation are also highly critical for us because Uruguay is a small country and has no critical mass in all the cutting-edge disciplines. This is why we need to be part of this cooperation schemes, to strengthen our human capital abroad and to make use of these new knowledge in our country. So, this is how we can close our knowledge gaps and boost innovation to make this transition towards sustainable development.

Xiaojing, we were talking about the new relationships, the post-ODA relationships and the possibility of having a more horizontal setting, continuing to cooperate. We were also speaking about being included or excluded from important spheres of knowledge management. But what in China's case, which might be very special, does the post-ODA world and the cooperation system look like?

Xiaojing Mao: China, even though it is already the second largest economy in the world, still faces a lot of challenges. But most donors have already left China. So, what can we do? As a researcher, I also think about what Karen has said: after graduation, when you are a high-income country, how do you position yourself? This is also a question for China. China always said: we are the largest developing country in the world. So, after we have reached high-income status, how should we position ourselves? Also, rethinking China's foreign assistance and its role as a southern partner: would it still be South-South cooperation? There are a lot of questions on this, already now and especially after you have graduated from the ODA list. As a researcher, I am also reflecting on these questions and I agree with Karen: we need to develop a more comprehensive methodology for measuring development because just using GNI per capita is a too simple way to measure a country's development situation. There will be more and more countries graduating from that list over the years to come. That means there will be fewer and fewer ODA recipient countries. But on the other hand, we also see that more and more emerging economies have started 
to provide aid, like Indonesia, which has established a fund to provide assistance to its neighbouring countries, and also Mongolia. The main resource is still South-South cooperation, but there are more and more aid providers in the international community, while there are fewer recipient countries, if they take the DAC criterion for ODA-eligibility as a basis. So, how would this international aid landscape change and how should we deal with this situation? What other innovative cooperation models are needed? As for aid itself, I think it is aiming to end itself.

Another issue is that we are facing more emerging development challenges like climate change and epidemic diseases; you will all know that China is currently suffering from the new coronavirus. And despite China's rapid development over the past few decades, we are still facing a lot of challenges related to climate change, the spread of epidemic diseases and also other environmental issues. So, there is still a lot of room and there are important areas where China can collaborate with the international community, including developed countries but also other developing countries. I totally agree with what Karen said: that every country has knowledge to share and this holds true for emerging economies especially because they may face similar situations and similar challenges. Therefore, peer learning is extremely valuable for all those countries.

Certainly, China is a large economy and there are high expectations from the international community. China is actively involved in a lot of global platforms, including development fora like the UN Development Cooperation Forum and a lot of sub-sectoral fora. We think that those multilateral platforms can play a good role in bringing all South-South cooperation providers and also traditional donors together, and in allowing views on international topics, including global public goods, to be exchanged. I think this is still very important, and even though we are facing some retreats in global cooperation, from my point of view most countries still consider multilateralism to be extremely valuable to the international community. So, global and regional platforms can play a very important role in strengthening those dialogues among different economies. In China, even though many countries have already stopped providing aid to the country, they still continue dialogues with us, like the UK, Germany, the US and a lot of other countries. There are a lot of bilateral dialogue mechanisms, but development only plays a small role in them. They focus more on critical economic issues. But more and more, especially on the part of traditional donors, they hope that they can include developmental issues in this mechanism. So, I believe that also after graduation, there will remain a lot of ways and channels for China to continue its collaboration with former donor countries. 
Noel, what would be the risks and the opportunities of graduation in your view? Noel González: Let me start with the risks. There are risks for developing countries having their development efforts not supported appropriately by international partners. They will be basically left alone or not properly accompanied, which is not very conducive to achieving the 2030 Sustainable Development Agenda, as set by the UN in 2015, and not compatible with building the global partnership for sustainable development that we agreed to establish in, again, the 2030 Agenda and the Addis Ababa Action Agenda. The first risk is that we will not achieve our goals with a lack of support due to a misconception on development that comes from political and domestic, but not from technical considerations by donor countries.

The second risk would be less support in tackling common problems. Also, for donor countries themselves: if you do not deal with the global and regional public goods as you need to, you are going to be less able to achieve goals like tackling climate change or achieving more managed and sustainable migration flows. So basically, if you simply leave countries on their own, then you are not going to be able to achieve the goals that you need to achieve. And we need to understand that they are not problems of developing countries or graduating countries or countries of the South, but problems that affect all humanity and we need to solve them together.

The third risk I see is that some of the donor countries that are withdrawing their international support are going to become less relevant as bilateral partners. When we have a broad understanding and a broad partnership on issues like development, then we can move together; we can increase the political dialogue with our partners. But if you cut off a very significant part of this partnership, then you are jeopardising the partnership as whole. So basically, if any given country simply stops providing development cooperation, then, not as a retaliatory measure but simply as a natural consequence, political dialogue is also going to be affected. This is not to be taken as a menace, it is simply a natural consequence of 'us' feeling that we are losing importance in our partners' agendas, so our partners cannot expect to have the same importance that they would have if they continued cooperating with us from a broader perspective. Therefore, these countries will lose relevance as international actors and this can have political consequences - because if we need to build new partnerships, then we are going to build them with whomever wants to support our national efforts. That is the fact of the matter; we are going to move towards this more multipolar world where we are going to build new partnerships. And then, the former role of certain actors, notably traditional donors, as standard setters and leaders in the world, is not going to be perceived in the same manner as it might have been before that. These are the risks. 
In terms of the opportunities, I think that there are opportunities. There are opportunities again to build a more horizontal world and build on the concept of co-responsibility, with more countries playing a bigger role in norm- and standard-setting in the world. In my view, that is positive for democracy: more different approaches that are going to have to come to the table.

There are certainly opportunities to increase South-South cooperation, a mechanism of development cooperation that has arisen since the 2000s. Triangular cooperation is also becoming more and more utilised by countries because we can potentiate everybody's assets and advantages. This has to be properly understood: it does not mean that southern providers have the knowledge, traditional donors have the resources and a third country is the beneficiary, from a more vertical perspective. Instead, the concept of co-creation in triangular and South-South cooperation is very important, combining both technical expertise and resources, human and financial resources, in order for us to find or create innovative and effective development solutions together. Therefore, triangular and South-South cooperation should also be strengthened in this coming era for international development cooperation.

Unfortunately, I fear that through this misconception on the role of development cooperation which we have been talking about, many of these potential benefits might be jeopardised by insufficient involvement or political will. And that will happen, again, for reasons that we do not think are technically sound or sufficiently thought-through, but more because of misperceptions that come from domestic political concerns.

Karen, what are the risks and the opportunities in your view? Maybe they also have to do with China?

Karen van Rompaey: We have just finished our last analysis of who our main cooperation partners are, looking at the data from 2018, and our main cooperation partner after ODA graduation is China. For us, international cooperation is a means to internationally distribute wealth and knowledge, but it is also a form of soft power and a means for mutual trust-building and to address regional and common global challenges. This is something that the donor community should take into account if they really want to leave countries completely on their own and lose that area of policy dialogue and of strengthening multilateralism, and the common ground to work on all the structural and systemic changes that are needed to really enable development at a global level.

In the end, I see one big opportunity that this graduation offers us. Perhaps it is a bit late for Uruguay, but I am glad that our graduation has led to us having a conversation at the global level on the issues that matter most: what do we understand as sustainable development, what needs do countries have relating to sustainable development, what are the capabilities and how can we build an international cooperation system that is based on those needs and the 
capabilities of countries in terms of sustainable development goals that we have jointly agreed to? In my view, this is an opportunity for the ODA graduation criteria to be revised and updated in the light of the 2030 Sustainable Development Agenda. In your introduction, you named that 2014 paper by the DAC committee. I remember reading this paper and the two scenarios it depicts in terms of what could happen if the DAC lowered the threshold for graduation to the World Bank's IDA eligibility level (that was not 12,000 but 7,000 dollars). So, I am really glad that we are having a conversation now, six years onwards, on how we can revisit the ODA criteria so that we do not leave countries behind but engage with those countries that are in transition towards sustainable development.

As regards post-ODA relations, Noel has mentioned all the instruments that we are developing. We really need to be open-minded, considering that new challenges are always arising, for which we will always need international cooperation. What is going to happen with the graduated countries that do not have the capacity to tackle these new challenges? Are they going to be left alone? This is something that I do not have an answer for, but we must also look into more innovative instruments. For instance, Uruguay has been giving the Netherlands cooperation on how to regulate cannabis production. So, this is South-North cooperation, something that was unthinkable a few years ago. Perhaps we do not have the funds to set up a big scale cooperation project, but we do have the knowledge/experience, so there should be funds that make it possible for Uruguayan knowledge or experience to be transferred to a northern country, a more developed country. We must be very creative in this big global challenge of transitioning together to a sustainable development model. We all have knowledge and experience that can be useful and fruitful for other countries, but we need a system designed in such a way that we can all contribute in an equitable and integral way, and so that we can all be part of this conversation and cooperation scheme to achieve sustainable development. 